\title{
El estado intensivo: Ontología y Política en Gilles Deleuze
}

\author{
The Intensive State: Ontology and
}

Politics on Gilles Deleuze

JULIÁN FERREYRA (Di

\section{Resumen}

En este artículo se analizan las perspectivas políticas que surgen de las diferentes interpretaciones existentes sobre la ontología que Gilles Deleuze construye en Diferencia y repetición. En primer lugar, se contemplan las implicancias de una visión restringida a su teoría de la Idea, donde el debate consiste en establecer si Deleuze se inclina por una prioridad virtual o una actual; en términos políticos, éstas lo acercan, respectivamente, a una genealogía soberana o una liberal. En un segundo momento mostramos cómo esta interpretación acotada se enriquece si se toma en cuenta el otro concepto fundamental del libro de 1968: la intensidad. De allí surgen versiones sofisticadas de ambas posturas: la prioridad actual ya no se identifica con un atomismo social, sino con la corporalidad intensiva del pueblo y las minorías que lo componen; el Estado como Idea social que emerge de la prioridad virtual, por su parte, ya no está "fuera del mundo", sino que está constituido por una materialidad intensiva. Finalmente, se mostrará que el elemento intensivo no alcanza para resolver las limitaciones de ambas perspectivas -tanto en lo especulativo como en lo político-, y la necesidad de superarlas hacia una reciprocidad absoluta, donde la inmanencia entre Idea e intensidad sólo encuentra distinción en los movimientos de plegado de un mismo espacio topológico, cuya traducción política es un Estado intensivo indisociable del pueblo que lo expresa y explica.

Palabras clave: Estado. Capitalismo. Intensidad. Idea.

\footnotetext{
a Universidad de Buenos Aires, Buenos Aires, Argentina. Doctor en Filosofía, e-mail: djulianferreyra@gmail.com
} 


\section{Abstract}

This paper studies the political perspectives that are gained by each of the existing interpretations on the ontology that Gilles Deleuze offers in Difference and repetition. Firstly, we consider the implications of a restricted vision, that only focuses in Deleuze's theory of the Idea, where the debate is whether a virtual or an actual priority must be held; in political terms, each of these positions make Deleuze keen either to a sovereign or a liberal stand. Secondly, we will point out that this restricted vision is enriched if the other fundamental concept of Difference and repetition is taken into account: intensity. Thus the sophisticated versions of the previous positions emerge: actual priority is no longer equivalent to a social atomism, but to the intensive corporeality of the people and the minorities that compose it; the State as a Social Idea that posits the virtual priority, on the other hand, is no longer "out of the world", but it is constituted by an intensive matter. Finally, we will show that the intensive element is not enough to overcome the speculative and political limitations of both perspectives, and the necessity of transcending them towards an absolute reciprocity, where the immanence of the Idea and the intensity only find its distinctions in the folding movements of one and the same topological space, which political translation is an intensive State that cannot be dissociated from the people that expresses and explains it.

Keywords: State. Capitalism. Idea. Intensity.

\section{Introducción}

Las controversias en torno a la ontología son, en el marco de los estudios sobre Gilles Deleuze (1925-1995), mucho más habituales que aquellas que versan sobre su filosofía política. En efecto, como muestra ejemplarmente Clisby (2016), podemos encontrar estudiosos que sostienen cada una de las alternativas interpretativas posibles en torno a la articulación de los conceptos ontológicos fundamentales de Diferencia y repetición (1968), tanto en lo que respecta a la relación actual-virtual como en el rol que en la misma puede jugar el concepto de intensidad. Menos controversia existe en torno a la filosofía política deleuziana. Es casi unánime la interpretación "libertaria", de acuerdo a la cual Deleuze sería aliado de lo que "mana y fluye" y enemigo de toda estructura societal (sea tribal, estatal, capitalista o cualquier otra de carácter "molar"). Su obra ofrecería herramientas teóricas de resistencia a las minorías, y claves de una organización "molecular” por fuera (o debajo) de esas máquinas de opresión. Ese es el posicionamiento inaugurado por Negri (1977), popularizado por Massumi en el ámbito angloparlante ("la fuerza en estado salvaje llega desde afuera para romper las coacciones 
y abrir nuevas perspectivas", 1992, p. 6) y cuyas muestras más recientes son — por citar sólo algunas entre la gran abundancia de estudios deleuzianos en la última década en ese tenor- Sztulwark (2013), Alliez y Lazzarato (2016), Pelbart (2017), Colson (2019) y Jouer (2018). Se trata de una postura que abreva en el autonomismo italiano ${ }^{1}$ y trabaja principalmente en torno a conceptos forjados por Deleuze junto a Guattari como rizoma, nomadismo, líneas de fuga, máquina de guerra, devenires, espacio liso y otros términos asociados (y muchas veces excesivamente confundidos en discursos que apelan a la jerga como elemento retórico). ${ }^{2} \mathrm{Si}$ controversia hay, es el grado de "anarquía” presente, es decir, si su anarquía es una alternativa radical al capitalismo o puede ser llevado hasta el "anarco-capitalismo" (como lo afirma apologéticamente Kœnig -2013- y como lo hacen críticamente Boltanski y Chiapello -1999-).

El objetivo de estas páginas es hacer confluir el enfoque ontológico y el político, es decir, considerar las implicancias que tienen para la filosofía política las diferentes posturas respecto al rol de los planos de la ontología. Para ordenar el debate seguiremos el esquema de Clisby (2016), quien indaga la posibilidad de un "dualismo secreto" en la filosofía deleuziana, que se abriría entre lo virtual y lo actual. Cada una de las relaciones posibles entre estos dos conceptos encuentran sus defensores: "reciprocidad", "prioridad virtual" y "prioridad actual". Veremos con más detalle en el desarrollo del texto estas divergentes posturas, que dan muestra de la falta de interpretaciones hegemónicas en puntos clave en los estudios deleuzianos. Esta falta de hegemonía también se observa en el rol que cumple el otro concepto fundamental de Diferencia y repetición: la intensidad. Nuevamente, Clisby -lo veremos- muestra que todas las combinatorias posibles están presentes en la bibliografía pero que, en todos los casos, se trata de un concepto crucial para comprender "la manera en que se relacionan lo virtual y lo actual" (CLISBY, 2016, p. 130) y, más profundamente, el sentido riguroso de la ontología de Gilles Deleuze.

\footnotetext{
${ }^{1}$ Sobre Deleuze y el autonomismo, cfr. Thuborn, 2003, pp. 11-12. Sobre las reservas de algunos autonomistas respecto al pensamiento deleuziano, cfr. Cuninghame, 2010, p. 156.

2 "El secreto o la intimidad anarquista puede ser identificada con lo abierto y los «espacios lisos» de la máquina de guerra nómade, donde los seres colectivos ya no están subordinados al «monopolio del poder orgánico, sino que son arrastrados por el «poder de un cuerpo turbulento en un espacio nómade»", Colson, 2019, p. 215.
} 
La relevancia de este debate interpretativo no es meramente especulativa. Como mostraremos a lo largo de estas páginas, tiene una incidencia práctica directa en el plano político. Cada combinatoria de la pareja actual/virtual y cómo se resignifica de acuerdo a la concepción de lo intensivo que la acompañe fortalece (y revive) posturas políticas clásicas: la concepción soberana encuentra su vínculo con la materia, mientras que el autonomismo se libera de las robinsonadas liberales para encontrar su forma específica de determinación. Sin embargo, el esquema de Clisby, al mismo tiempo que ordena el debate, nos encierra en dilemas irresolubles. Sólo desmontando el "dualismo secreto" podremos dar lugar a toda la potencia actual de la ontología política deleuziana.

\section{Desarrollo}

\section{El dualismo secreto}

Lo virtual y lo actual son conceptos que recorren en extenso la obra de Deleuze, desde sus tempranos trabajos sobre Bergson hasta los dos últimos textos que escribió antes de morir en 1995: el titulado, justamente, "Lo actual y lo virtual" (DELEUZE, 1996) y "La inmanencia: una vida...” (2003). Sin embargo, el análisis de Clisby (2016) se emplaza en el momento de mayor espesor: Diferencia y repetición. Allí, lo virtual es desarrollado principalmente en el capítulo 4, en torno a teoría de la Idea. Lo virtual no es un ser inefable que se oculta en las sombras de la experiencia, sino un plexo de Ideas cuidadosamente determinadas: "Lejos de ser indeterminado, lo virtual está completamente determinado” (DELEUZE, 1968, p. 270). ${ }^{3}$ La determinación virtual no se confunde, por ello, con el "conjunto de determinaciones propias de la existencia actual" (ibid), dado que existen dos formas de determinación: una virtual y una actual, que configuran dos planos ontológicos distintos. El debate que reproduce Clisby se centra en la jerarquía entre estos dos planos: ¿cuál tiene prioridad, si es que alguno la tiene?

La opción más intituitiva, avalada por ciertos giros con los que Deleuze mismo se expresa (cuando se refiere, por ejemplo, a la actualización de lo virtual

\footnotetext{
${ }^{3}$ Sobre el carácter virtual de la Idea y su carácter determinado y real, cfr. Deleuze, 1968, p. 269-271.
} 
como un proceso de verdadera creación -1968, p. 273-), es que hay una prioridad virtual, es decir, que el dinamismo ontológico se encuentra en el proceso de determinación propio de las Ideas y la determinación actual es meramente pasiva. La prioridad virtual "abstrae el poder de creación hacia el ámbito de lo virtual, vedando a los seres actuales la capacidad de interactuar verdaderamente" (CLISBY, 2016, p. 128-129). Sin embargo, esta lectura es incompatible con una plena inmanencia donde todas las dimensiones deberían tener un rol determinante. Implicaría una trascendencia de lo virtual y, en su traducción política, un verticalismo hiperbólico (la soberanía que se ejerce "de arriba hacia abajo") imposible de articular con los aspectos micro-políticos del pensamiento deleuziano. No es por ello extraño que Clisby sólo convoque como representantes de esta postura a dos críticos severos del deleuzianismo (BADIOU, 1997, y HALLWARD, 2006).

La segunda alternativa (la reciprocidad actual/virtual) aparece como la más sensata: "lo virtual no puede ser abstraído de los estados de cosas actuales a los cuáles está conectado”. Williams (2005), Hughes (2009), Somers-Hall (2012) y Smith (2012) son los intérpretes de renombre que Clisby encolumna en esta postura. Sin embargo, este posicionamiento de vía media deja pendiente el cómo, la forma bajo la cual lo virtual está conectado con los estados actuales de cosas. Esta pregunta es de alta relevancia política. ¿Cómo se vincula lo virtual con los individuos y las formas sociales que se debaten en lo actual? Dado que la concepción soberana de la organización política no niega la necesidad de una articulación (la mediación, la representación, la figura de cristo y las instituciones no tienen otro sentido), la mera enunciación de la reciprocidad no resuelve los cuestionamientos de fondo a la prioridad virtual. Para sostenerla — como haremos nosotros en el último apartadohace falta una visión completa de la ontología deleuziana y su funcionamiento, y no un mero ida y vuelta entre los planos — o su yuxtaposición.

La tercera vía posible no encuentra defensores cuando Clisby presenta la pareja. Nadie habría encontrado en Deleuze una prioridad actual en tanto tal postura, en apariencia, correspondería a un empirismo vulgar, que buscaría encontrar en lo dado el prius ontológico deleuziano; en términos políticos: un individualismo liberal, donde los hombres solos y aislados serían los "átomos" de base. Insostenible, incluso en el más sesgado y superficial abordaje del filósofo francés. Curiosamente, será 
justamente esta la postura que Clisby mismo sostendrá en sus conclusiones: "si hay alguna prioridad dada por Deleuze, está del lado de lo actual' (CLISBY, 2016, p. 146). El sentido de este giro (y por ello Clisby lo presenta en la conclusión) depende de introducir un nuevo plano ontológico: el intensivo. Es el carácter intensivo de lo actual (y no meramente extensivo) lo que permite distinguir las posturas autonomistas o anarquistas (que buscan encontrar el fundamento político en las multitudes intensivas) de las liberales (que buscan el fundamento en los individuos "concretos").

La carta que guarda Clisby bajo la manga hasta el final de su artículo pone en evidencia un desplazamiento del par actual/virtual hacia un nuevo dualismo, mucho más relevante ontológicamente: Idea e intensidad, los dos conceptos fundamentales de Diferencia y repetición, que son expuestos respectivamente en los capítulos cuatro y cinco de la obra. Nuevamente existen intepretaciones para sostener todas las opciones: la intensidad aparece como propiedad de lo virtual (WILLIAMS, 2003), como modalidad de lo actual (ROFFE, 2012) y como un registro ontológico totalmente separado (DeLanda, 2005). Incluso existen quienes se inclinan por dejar directamente de lado lo virtual (Voss y Roffe, 2017).

Este nuevo dualismo impacta en todas las posturas ontológico-políticas. Así como la prioridad actual se despega de la metafísica liberal, la prioridad virtual encuentra en la intensidad un nuevo vigor, que permite resignificar la concepción soberana de lo político, donde el Estado no sea una máquina fría y formal, sino elemento constitutivo de la materia. Por otra parte, el destino de la reciprocidad también se verá radicalmente modificado, ya que la intensidad es una forma inmanente de relación recíproca entre lo virtual y lo actual que desbarata los intentos de introducir una instancia mediadora representativa entre los planos de la ontología. Analizamos a continuación en detalle cada una de estas posturas ontológico-políticas.

\section{La política de la prioridad actual-intensiva: de abajo hacia arriba por los callejones}

El presupuesto básico del pensamiento político de Deleuze es la frase inicial de los Grundrissse de Marx: "Individuos viviendo en sociedad, tal es naturalmente el 
punto de partida" (1971, p. 3). En efecto, Deleuze jamás suscribiría la "absurdidad histórica, antropológica, psicosocial, sociológica, y filosófica -salvo para los seguidores de la metafísica liberal- de las robinsonadas" (DOTTI, 2011, p. 427). ${ }^{4}$ No podemos partir de los individuos "solos y aislados" ya constituidos (ya subjetivados) para comprender los procesos sociales. No hay un atomismo de base, ya que las relaciones preceden a sus términos (leit-motiv deleuziano que ya aparecía en su primer libro, Empirismo y subjetividad, de 1952). La prioridad meramente actual no tiene en el plano político ninguna posibilidad de ser lo que sostiene Deleuze.

Sólo una prioridad actual-intensiva (la postura ontológica que Clisby defiende en su artículo) hace por lo tanto posible la interpretación hegemónica de los estudios políticos deleuzianos. Da lugar a un anarquismo sofisticado donde existen "relaciones y asociaciones entre seres (como así también los conflictos entre ellos)" pero éstas "no son externas a lo que los constituye" sino "asociaciones verdaderamente revolucionarias capaces de modificar el orden existente desde abajo hacia arriba, de contener otro mundo" (COLSON, 2019, p. 62) ${ }^{5}$. Es sofisticado, en tanto plantea formas de organización y no meramente la resistencia a todo tipo de lazo, pero anarquismo al fin, en tanto rechaza todo tipo de máquina social. Estas máquinas aparecen en El anti-Edipo (DELEUZE y GUATTARI, 1972) como tres formas de socius (primitiva, despótica y capitalista), que luego se multiplican y complejizan en Mil mesetas (DELEUZE y GUATTARI, 1980), donde también se incorpora una "dialéctica" entre los Aparatos de captura y las Máquinas de guerra. El germen de las máquinas sociales puede rastrearse en Diferencia y repetición como Ideas sociales, donde las diferenciales, sus relaciones y las singuralidades que producen encuentran como único ejemplo al capitalismo (DELEUZE, 1968, p. 240-241). ${ }^{6}$ En tanto su genealogía se remonta a la Idea, las máquinas sociales, desde el punto de vista ontológico implican una prioridad virtual. En consecuencia, las posturas autonomistas se van forzadas a tomar una prioridad actual extrema, ya que su premisa fundante es que las grandes formas sociales son siempre - $y$ únicamente- aparatos represivos que deben ser combatidos por todos los medios.

\footnotetext{
${ }^{4}$ Dotti hace aquí referencia, también, al inicio de los Grundrisse.

${ }^{5}$ Para una análisis en profundidad de la relación de Deleuze con el anarquismo, además del libro de Colson, cfr. Van Heerden y Eloff, 2018.

${ }^{6}$ El ejemplo de Idea social es construido a partir de la caracterización estructuralista del Capital realizada por Althusser y su equipo.
} 
Enorme apoyo textual tiene esta lectura. En Diferencia y repetición, la Idea social es el capitalismo. En El anti-Edipo, todas las máquinas sociales aparecen bajo caracterizaciones terribles: la crueldad de los primitivos, el despotismo del Estado, la producción de miseria capitalista; codificación, sobrecodificación y axiomatización son puras herramientas de la servidumbre. La misma carga axiológica aparece en Mil mesetas, en la exposición de los Aparatos de captura como grandes estructuras sociales inherentemente represivas, frías y crueles. Una prioridad virtual nos ataría a ellas y toda acción de lo actual sobre lo virtual (como acción humana) estaría condenada a encadenar los flujos de deseo.

La lucha contra el capitalismo se hace imperiosa, dado que es "un sistema económicamente floreciente y socialmente desastroso, marcado por un lado por el empobrecimiento de la población activa, el agravamiento de la desocupación y la precarización del trabajo, y por otra parte por el crecimiento de las tazas de beneficio del capital” (Karsenti, 2000, p. 143). Pero el Estado, ese elefante reumático, no puede ofrecer una alternativa: "La constitución de una nueva voluntad políticaestatal" a pesar de sus logros en materia de bienestar y derechos humanos "no ha alcanzado a sustituir (ni por «arriba» ni por «abajo») el poder de la razón neoliberal” (SZTULWARK, 2013). En el mismo sentido, Alliez y Lazzarato indican que, en la lucha contra el capitalismo, no se puede buscar auxilio en los Estados o en un “pacto social” (2016, p. 428).

El plano actual queda entonces como único territorio para una lucha política que elude las "robinsonadas" de la metafísica liberal a través del elemento intensivo: "Se trata de tomar en serio el mundo de las intensidades", dice Sztulwark (2013). ${ }^{7}$ Allí es donde la propuesta ontológica de Clisby toma toda su dimensión política. Las grandes organizaciones sociales son reemplazadas por "disparidades” sociales:

Todo fenómeno remite a una desigualdad que lo condiciona. Toda diversidad, todo cambio remiten a una diferencia que es su razón suficiente [...] Llamamos disparidad a este estado de la diferencia infinitamente desdoblada, que resuena al infinito. La disparidad, es decir la diferencia o la intensidad (diferencia de intensidad), es la razón suficiente del fenómenos, la condición de lo que aparece (DELEUZE, 1968, p. 286-286).

\footnotetext{
7 También DeLanda había intentado pensar lo social en el marco de la teoría de las intensidades (2010, p. 11).
} 
La razón de lo social no son los individuos constituidos, ni las relaciones ideales y partes notables que encarnan (su rol en la "estructura") sino las individuaciones, los afectos que nos arrastran en constantes devenires, y nos dan identidades precarias que siempre dependen de una diferencia, de las diferencias en el modo de afectar y ser afectados y de las diferencias de nuestra potencia: hasta dónde llega lo que podemos hacer y padecer. Esa intensidad es lo que coagula en los fenómenos de masas, en las poblaciones que se lanzan a las calles con su cuerpos y cantos para poner coto a los avances represivos y para construir nuevos mundos desde esa disparidad constitutiva: "Tiene importancia que los cuerpos se reúnan [...] estas formas de performatividad corporeizada y plural son componentes esenciales de cualquier comprensión de «el pueblo», aun cuando sean necesariamente parciales" (BUTLER, 2017, p. 15). La lucha política se construye desde abajo, y solamente desde abajo.

\section{Los límites de la intensidad}

Ahora bien, esta vía de análisis también ha sido tomada para señalar que la filosofía deleuziana, lejos de ser una "máquina de guerra" contra el capitalismo en general y su estadio neo-liberal en particular, es por el contrario el vehículo para pensar su reivindicación y aceleración. Algunos lo plantean en sentido apologético: "Podemos imaginar una lectura alternativa de Deleuze -a mi entender más justa y más fiel en el fondo a su pensamiento- de acuerdo a la cual, lejos de condenar al capitalismo, busca exacerbarlo. ¿Deleuze, anarquista en su estética, y anarco-capitalista en su filosofía?” (KCENIG, 2013, p. 132) ${ }^{8}$. Los más, sin embargo, lo usan como ariete para demoler las pretensiones del deleuzianismo. Badiou inició esta tendencia con un pequeño escrito, el "fascismo de la papa" (1977), donde el rizoma aparecía como la clave de bóveda del secreto del fundamento del capitalismo; Boltanski y Chiapello lo acusaron de protagonizar la constitución del nuevo espíritu del capitalismo (1999) y Michéa de confiar que el mismo desarrollo del capitalismo

\footnotetext{
${ }^{8}$ En esa línea podemos encontrar también a Mengue (2003), quien afirma: "con el capitalismo contemporáneo, Deleuze tiene finalmente lo que quería" (p. 121).
} 
conduciría a la revolución, en la saga con los aceleracionistas que se inspiraron en él (2013). En lugar de ser una alternativa al capitalismo, el rizoma sería el modelo de sus redes abiertas (BOLTANKSI y CHIAPELLO, 1999, p. 174), mientras que el perspectivismo ético (más allá del bien y del mal), su sistema de valores (p. 237). Su "crítica de todo lo que pudiera cumplir el rol de un «punto fijo» como punto de referencia, sea, por ejemplo, el estado, la familia, las iglesias y en general todas las instituciones" y su defensa de la "movilidad, la fluidez, los «nómades», susceptibles de circular, mediante múltiples metamorfosis en las redes abiertas" (ibídem) serían, en suma, constitutivas de aquello que declara querer combatir. Los nómades son los camellos posmodernos que cargan voluntariamente con la producción de un valor que nunca será de ellos.

Si estudiamos las respuestas que los deleuzianos ensayaron a tales acusaciones, observamos que es habitual el recurso al plano intensivo, distinguiéndolo del orden extensivo (y el empirismo vulgar que supone limitarse a él) al que muchas críticas parecen reducir su pensamiento. Jeffrey Bell recurre, justamente, a la distinción entre las cualidades intensivas y extensivas (2011, pp. 9-10). Sólo las extensivas pueden subordinarse a un función identificable (i.e.: el desarrollo del capitalismo según BOLTANSKI y CHIAPPELLO), mientras que las "intensivas aseguran la transformación y metamorfosis de lo extensivo e identificable" (p. 10) y son "procesos sin objetivo ni fin" (p. 11). Por ese motivo, el capitalismo busca contener "lo que Deleuze y Guattari ven como el limite absoluto o desterritorialización que haría fracasar la posibilidad de las relaciones extensivas sobre las cuales el capitalismo está construido" (2016, p. 137). Pál Pelbart, sopesando también los argumentos de Boltanski y Chiappello, acepta que "el capitalismo se haya apropiado de ese espíritu, de esa lógica, de ese funcionamiento [de las conexiones rizomáticas], no puede dejarnos indiferentes”, pero se inclina por "mapear la fuerzas reales que están «operando» y volviendo caducas las viejas formas" (2016, p. 249-259)9. Mapear las fuerzas reales indica el camino de una

\footnotetext{
${ }^{9}$ Pál Pelbart remite a Karsanti, quien había afirmado: "Manteniéndonos sobre un plano ontológico, podemos decir que las fuerzas son realidades que tienden siempre a desbordar las fronteras a partir de las cuales se opera su repartición. Son inventivas, imprevisibles, creadoras. Inventan modalidades de ejercicio que unas veces permiten introducir otras fuerzas en un campo cerrado que habíamos querido trazar, y otras veces
} 
política intensiva, donde el "mapa" de las intensidades reemplaza al "calco" extensivo y, sobre todo, la fuerza de lo intensivo-actual desborda el trabajo opresivo de las grandes Ideas sociales (las "viejas formas", formas por definición represivas). En suma, la estrategia consiste en distinguir lo actual meramente extensivo, de un actual-intensivo donde lo comunitario surgiría de la síntesis asimétrica de lo sensible tal como lo caracterizamos en el apartado precedente.

Los argumentos centrales de Boltanski y Chiapello siguen sin embargo a mi entender sin ser atendidos: las redes de la inmanencia (sean intensivas, sean extensivas) no son antimorfas del capitalismo. Como los años han mostrado desde la célebre frase de El anti-Edipo que está en el origen de aceleracionismo ("en ese sentido, todavía no hemos visto nada”, Deleuze y Guattari, 1972, p. 285), el desarrollo mismo del capitalismo no permite desmontar sus leyes ni contrariar su lógica. No alcanza con lo "nuevo" y lo "creador" para superarlo, justamente porque el capitalismo es esencialmente creador, y tampoco alcanza con el carácter intensivo de la lucha como elemento suficiente para pensar su eficacia, dado que lo que se combate también se basa en un régimen intensivo. Todas las máquinas sociales son tan intensivas como ideales, y el capitalismo en particular es un máquina delirante sin objetivo ni fin, para la cual el anarquismo es un medio de desarrollo y no un obstáculo, y mucho menos, un elemento para su catástrofe.

Las asociaciones nómades fundadas en "máquinas de guerra rizomáticas desterritorializadas" pueden ser subsumidas por un cuerpo más potente. Es sin duda esto lo que indica la ética spinozista tal como Deleuze la interpreta: el pez grande se come al chico, tal es la ley natural. En ese sentido, la forma-Estado que sistemáticamente impugna la perspectiva actual-intensiva ha mostrado su eficacia para proteger las asociaciones nómades, y también en limitar los daños más concretos del capitalismo, haciendo llegar alimentos, vivienda y educación a las zonas ignoradas por las redes de producción, circulación y consumo del capitalismo. Ante el hecho concreto del hambre y la miseria, y en la defensa de los derechos de los oprimidos, las políticas activas estatales han mostrado una capacidad que Deleuze y Guattari no ignoran ni niegan (si bien las relativizan al catalogarlas de especificar" (2000, p. 159-160). 
"luchas axiomáticas", es decir, en el seno de la lógica del capital, cfr. Deleuze y Guattari, 1980, p. 588). El nivel de organización, planificación y la escala de recursos que implica resolver o paliar los problemas materiales de las crecientes poblaciones mundiales, o sostener nuevos derechos en contra de los valores establecidos y la lógica de dominación imperante (derechos de las mujeres, de las minorías, del medio ambiente) requieren macro-estructuras, y no son tareas que la política pueda dejar de lado.

\section{Prioridad virtual: de arriba hacia abajo sin despotismo}

La dispersión en redes de minorías, el espontaneísmo al que queda librada su organización, la inexistencia de todo diagnóstico sobre la lógica de las relaciones que sustiende a su existencia implica una horizontalidad política "donde se encuentran en pie de igualdad las pretensiones y postulaciones pluralistas que provienen de tantas subjetividades autónomas, cuantas visiones particularistas, intereses corporativos, facciones y diversidad de opiniones se den" (DOT'TI, 2009, p. 81-82). Por incómodo que pueda resultar a la sensibilidad de los defensores de una política intensiva de corte deleuziano, la distinción entre facciones y minorías debe ser establecida. La respuesta de Dotti en la tradición del pensamiento estatal es unívoca: sólo la representación estatal de fundamento trascendente, que legitima al soberano a erigirse como juez ante los diferendos puede evitar que el enfrentamiento entre facciones escale hasta la destrucción total. Este camino podría llevarnos a otra vertiente de filosofía política (la que abreva, como Dotti, en la genealogía Hobbes-Hegel-Schmitt) y condenar al deleuzianismo como parte de las "alternativas teóricas post" que "ficcionalizan (no-)sujetos de la (no-)política intencionalmente imprecisos, deconstruídos, fragmentarios y fluidos” (Dotti, 2009, p. 16). De arriba hacia abajo, o la catástrofe.

Ahora bien, la soberanía tiende a caer en el despotismo, y los horrores objetivos que jalonan la historia de los Estados modernos en su etapa de mayor vigor, así como su servilismo ante los intereses del capital financiero en la etapa actual, generan el justificado escepticismo que reina en los estudios deleuzianos 
respecto a lo estatal. Sin embargo, la cuestión toma otro cariz cuando el fundamento de legitimidad del Estado no es ya Dios ni alguna de sus sombras, sino una Idea en sentido deleuziano, con la multiplicidad como prius, y cargada de la potencia de las relaciones diferenciales y las singularidades pre-individuales ( $f f r$. Ferreyra, 2011-2012). A pesar de ello, las críticas ontológicas a la prioridad virtual (fuera del mundo) infectan también esta alternativa a causa de su "indiferencia a la política de este mundo" (Hallward, 2006, p. 162). Desde la perspectiva de una prioridad meramente virtual donde lo único relevante sea la idea y su actualización, Hallward estaría en lo cierto. Sin embargo, como hemos visto, una concepción completa de la ontología deleuziana debe incluir lo intensivo en el movimiento de lo Ideal. Un movimiento vertical, de arriba hacia abajo, pero no espiritual, sino constitutivamente corporal y material en tanto intensivo. En ese sentido, en Deleuze hay un empirismo de la Idea:

Hay entonces un empirismo de la Idea. En los casos más diversos, debemos preguntarnos si nos encontramos ante elementos ideales, es decir sin figura ni función, pero recíprocamente determinables en una red de relaciones diferenciales. Por ejemplo, las partículas físicas, ¿están en ese caso, y cuáles de ellas? (Deleuze, 1968, p. 356).

La Idea deleuziana es tan concreta, tan material, que existe un "empirismo de la Idea", que consiste en rastrear (problemáticamente), los elementos virtuales en los casos concretos: en cada caso, debemos preguntarnos si nos encontramos ante elementos ideales, si las manifestaciones sociales están o no en ese caso, y cuáles de ellas ¿Qué relaciones diferenciales y singularidades políticas y jurídicas se encarnan en cuáles relaciones sociales? Esta propuesta puede aplicarse a la Idea social capitalista, como lo hace específicamente Deleuze (¿cuáles son sus diferenciales [la fuerza de trabajo, la fuerza del capital], cuál es su relación recíproca [la subsunción real] y qué produce [plusvalía de flujos]?) pero también a una Idea de Estado (el rol de la moneda/impuesto, de la tierra, del trabajo, como hacen Deleuze y Guattari [1980, pp. 554-555, cfr. Ferreyra, 2016]) e incluso a las minorías. Son temas de una cuidadosa analítica ontológico-política, para las cuales el cruce de la teoría de la Idea en Diferencia y repetición con el vínculo entre nociones comunes (relaciones características) y potencia en su estudio sobre Spinoza ofrece potentes herramientas, y permite reivindicar la supuestamente maldita figura del aparato de Estado. Así, se 
puede concebir un Estado deleuziano que no sea una mera forma trascendente y eterna, sino que encuentre, como quieren los abanderados del "pensamiento estatal", su dinámica en su desarrollo orgánico a través de sus agentes ( $f f r$. Abad y Cantarelli, 2012, y Abad y Amador, 2018).

La prioridad virtual-intensiva ofrece la posibilidad de encontrar en las Ideas algo distinto de la fuente de los aparatos represivos: una instancia legítima que, lejos de reprimir las instancias surgidas del dinamismo intensivo de la sociedad y sus fuerzas minoritarias, sea capaz de protegerlas: "protegerlas forma parte de las tareas principales del Estado" (DOTTI, 2011-2012, p. 443). Sólo la potencia del despliegue de una nueva Idea puede combatir empíricamente la potencia desplegada de otra Idea: Estado contra Capital sería así la única batalla política relevante.

\section{La reciprocidad topológica absoluta en los pliegues del ser común}

Sin embargo, si se trata de concebir a la Idea y su actualización en el plano de la siempre conflictiva arena política, si se trata de usarla como herramienta de lucha contra la lógica social imperante con un criterio vinculado a lo bueno y lo malo para los existentes, reaparecen las acusaciones de Hallward: "Hay poco espacio en la filosofía de Deleuze para relaciones de conflicto o solidaridad [...] Deleuze escribe una filosofía de la diferencia (virtual) sin otros (actuales)" (2006, p. 162). Incluso si tomamos en cuenta el "empirismo de la Idea" que Deleuze afirma, no queda claro el rol de los "individuos concretos" y los conflictos sociales en la determinación progresiva. ¿No somos acaso testigos mudos de la lucha de los dioses-Ideas en el olimpo virtual, que en todo caso impactan en nuestra sensibilidad a través de su aspecto intensivo? Allí, la prioridad actual-intensiva parecía ofrecer la respuesta: toda una analítica de la multiplicidad concreta, de sus minorías y sus individuaciones, del pueblo y sus luchas, de la servidumbre y la libertad. Sin embargo, sus insuficiencias nos llevaron a evaluar la prioridad ideal. La alternancia entre dos perspectivas insuficientes no resuelve el problema en cuestión. El "argumento Alicia" contra el buen sentido ("Alicia deviene más grande de lo que era pero por ello mismo deviene más pequeña de lo que es ahora”, 
Deleuze, 1969, p. 9) es insuficiente. Debemos arrancarnos de un ida y vuelta estéril de un sentido a otro de la ontología, de lo virtual a lo actual y de lo actual a lo virtual.

Para ello, hay que superar las insuficiencias del esquema de Clisby, que al tomar como punto de partida el dualismo virtual/actual hace que lo intensivo aparezca como un añadido, un parche o una bisagra entre esos planos. La reformulación que Deleuze realiza de la ontología es mucho más radical, ya que disuelve toda posibilidad de concebir un plano en forma autónoma de los demás, sea éste virtual, intensivo o actual/extensivo. Un empirismo que sólo contemple lo virtual-intensivo es insuficiente, ya que la realidad también está hecha de las partes extensivas que nos componen, de nuestro hambre, nuestro hedor ${ }^{10}$ y nuestras contracciones constitutivas. Las relaciones intensivas, aunque actuales, no llegan a dar cuenta de las leyes de composición y descomposición, y las razones de nuestra potencia e individualidad. Sólo un entrelazamiento radical de armazón [charpente] y sensación permite a lo concreto tener sentido y duración. ${ }^{11}$ Las prioridades son falsas y sólo hay una reciprocidad absoluta, que no implica un alternar sino una dinámica de determinación conjunta, un movimiento en el que ningún plano se modifica sin alterar al resto. Ni arriba ni abajo: la inmanencia del Sahara (DELEUZE, 2002, p. 81) con su topología de n-dimensiones ${ }^{12}$ desmonta los falsos problemas que suelen agobiar el debate político. La ontología deleuziana ofrece así una diagonal entre la verticalidad soberana y la horizontalidad de los valores con espíritu capitalista.

El concepto fundamental para comprender este funcionamiento topológico de la ontología es el pliegue. Este concepto será central en la obra de Deleuze de la segunda mitad de los '80, pero es mentado en Diferencia y repetición a través de las nociones de perplicación, complicación, implicación, explicación y replicación (todos estos términos contienen la partícula “pli”, pliegue). La quíntuple determinación del pliegue "rompe" el dualismo secreto. Mientras la perplicación expresa la dinámica de la Idea, 13 la "trinidad"

\footnotetext{
${ }^{10}$ Sobre la necesidad de tomar filosóficamente en cuenta el carácter sucio y "hediondo" de la existencia, cfr. Kusch, 2000, p. 9-19.

11 "Sensación y armazón. Es su entrelazameinto [...] A la vez hacer que la geometría sea concreta o sentida, y dar a la sensación duración o claridad" (DELEUZE, 2002, p. 106).

12 Sobre el rol de la topología en la relación Idea-intensidad, cfr. Santaya, 2019.

13 Deleuze reserva "perplicación" para la determinación Ideal-virtual: "Proponemos el nombre perplicación para designar este estado distintivo y coexistente de la Idea" (p. 242); "hemos llamado perplicación a este estado de las Ideas-problemas, con sus
} 
complicación-implicación-explicación corresponde a distintos aspectos de los sistemas intensivos. ${ }^{14}$ No hay entre ambos planos sin embargo dualismo, sino inmanencia absoluta, dado que las series intensivas complicadas se corresponden con las series ideales perplicadas: "Llamamos complicación al estado del caos que retiene y comprende todas las series intensivas actuales que corresponden con esas series ideales [las producidas por la perplicación de la Idea]” (DELEUZE, 1968, p. 359).

La proximidad entre los planos es de hecho tan grande desde la perspectiva de la perplicación-complicación, que surge el riesgo de que todos los planos caigan uno arriba del otro, lo cual implicaría una catástrofe para la filosofía (Deleuze, 2007, p. 31). ¿Qué rol cumple cada uno en la "sinfonía discordante" de lo real? ¿Cómo se determinan unos a otros en un movimiento conjunto? Justamente por ello hay una quintuplicidad del pliegue, y la complicación forma parte de una trinidad intensiva. En tanto implicadas (y no sólo complicadas) las intensidades expresan Ideas, y, al hacerlo, introducen un "nuevo tipo de distinción” en el plano virtual (p. 325). Plegándose, lo real se arranca de la coexistencia y el caos, ya que cada intensidad, en tanto envolvente (es decir, implicada), "sólo expresa claramente ciertas [relaciones diferenciales] y ciertos grados de variación" (ibidem). Es el mismo pliegue, entonces, lo que introduce distinciones en lo virtual, es decir, inyecta creación. No hay un afuera. Se trata de una topología donde los movimientos constituyen la determinación. Si cada pliegue implica la expresión clara de otras relaciones virtuales, el plegado produce lo real-determinado. Este real determinado es actual (se trata de "series intensivas actuales", p. 359, mi énfasis), ${ }^{15}$ pero no sólo actual-intensivo, sino también extensivo. La explicación es necesaria para que lo creado exista en el tiempo empírico de nuestra vida en la tierra, con sus contracciones constitutivas.

multiplicidades y variedades coexistentes, sus determinaciones de elementos, sus distribuciones y singularidades móviles, sus formaciones de series ideales en torno a estas singularidades" (1968, p. 359).

14 “La trinidad complicación-explicación-implicación da cuenta del conjunto del sistema, es decir [1] del caos que sostiene todo, [2] las series divergentes que salen y entran de él, y [3] del diferenciante que las relaciona unas con otras. Cada serie se explica o se desenvuelve, pero en su diferencia con las otras series que implica y que la implican, que envuelve y que la envuelven, en este caos que complica todo" (Deleuze, 1968, pp. 161-162, la numeración entre corchetes es mía).

${ }^{15}$ Esta conclusión -y esta cita- la debo a la audacia y a la solidez argumenta de Rafael Mc Namara (2019). 
Si la determinación de lo existente fuera meramente extensiva, sólo prolongaría lo ya-aquí. Sin embargo, el quinto valor del plegado, la replicación, señala que lo actual-extensivo no está "abandonado", sino cargado de lo virtual al que nunca trasciende: "los centros de envolvimiento dan testimonio de la persistencia de los problemas, o de la persistencia de los valores de implicación en el movimiento que los explica y los resuelve (replicación)" (DELEUZE, 1968, p. 359-360). En lo actual (la extensión que explica y las especies y partes que resuelven) persisten tanto las Ideas (los problemas) como la intensidad (los valores de implicación). El uso del mismo término (persistencia) y su reiteración en la misma frase para añadir énfasis marca que no hay actual sin la acción conjunta de los dos planos metafísicos. Lo real que exige la perplicación en la Idea, con su constante creación de nuevas armazones para el flujo del mundo, pero también implicación para que determinadas ideas se expresen en lo actual y explicación, para que existan.

Si la explicación es parte del mismo espacio topológico, entonces los movimientos de partes extensivas que realizamos en el presente también tienen efectos en la totalidad. Ese es el "movimiento en lo actual que abre el objeto a una nueva virtualidad" (CLISBY, 2016, p. 127), que determina ciertas ideas a actualizarse. Lo virtual no está por lo tanto fuera del mundo, no es independiente de las minorías, los cuerpos y las masas que componen el tejido social (en su carácter necesariamente intensivo y extensivo). Así, nuestras luchas tienen sentido y las Ideas sociales no son sólo máquinas de represión, sino constitutivas de todo ser común (incluso de las comunidades más radicalmente anarquistas), mientras que lo actual no es mero fluir y devenir, sino determinante en la formación de las grandes relaciones sociales que pueden proteger o condenar nuestra existencia.

\section{Consideraciones finales}

Desde el punto de vista político, el diagnóstico deleuziano ${ }^{16}$ parte desde un pliegue determinado (la hegemonía capitalista). Este pliegue implica determinadas relaciones diferenciales y singularidades, distintos grados de intensidad, con sus

\footnotetext{
${ }^{16}$ Sobre la relevancia política del diagnónstico, cfr. Deleuze y Guattari, 1991, p. 107.
} 
profundidades y distancias, ciertos despliegues de partes y cualidades actuales (los individuos humanos, vivientes y maquínicos) y, finalmente, ciertas "replicaciones" que mantienen vivo aquello que siempre parece al borde de fallecer. En las condiciones del capitalismo “supuestamente triunfador” (Deleuze y Guattari, 1972, p. 163), nuestra vida en lo actual se desarrolla sufriendo los embates de un pliegue hostil, irrespirable. Queremos luchar, queremos respirar. ¿Podemos hacerlo? ¿Hay algo que podamos hacer y no sea una mera ilusión de actividad, cuando sólo padecemos el maquinismo universal?

Afortunadamente, el pliegue social sobredetermina y hegemoniza, pero no totaliza. Es la expresión clara de ciertas relaciones y singularidades, pero sólo una entre las infinitas que encierra la gran complicación universal. Las minorías, en sentido técnico deleuziano, son justamente envolvimientos que siguen pliegues distintos del hegemónico, con otra intensidad, otras relaciones de movimiento y lentitud, y otra explicación en cuerpos concretos. Expresan, así, otras Ideas. Por su falta de escala, por su potencia reducida, serán violentados, forzados a cambiar de posición por el pliegue hegemónico, hasta lo insoportable, hasta la extinción misma. Hace por tanto falta una catástrofe que haga desmoronar los pliegues dominantes. La catástrofe social es, sin embargo, un gigantesco peligro (inconmensurable con la catástrofe estética que el artista tiene que atravesar para poder crear -Deleuze, 2002, p. 95). Esta catástrofe no debe hundirnos, no puede absorberlo todo. Debe potenciar la vida humana, no aniquilarla. Nuevas distinciones deben surgir. Hace falta tomar el ritmo de otro pliegue social, que exprese una Idea social de otra naturaleza. Pueden ser ideas evanescentes, que duren lo que un impulso revolucionario y valgan en su evanescencia. ${ }^{17}$ Pero pueden ser ideas capaces de durar en el mundo, ${ }^{18}$ armazones, pliegues estatales que no sean la encarnación de una Idea trascendente, que no sean un Deus mortalis, sino la inmanencia de una determinación ideal-virtual e intensidades absolutamente actuales, para un empirismo trascendental político de la emancipación.

\footnotetext{
17 “La victoria de una revolución es inmanente y consiste en los nuevos lazos que instaura entre los hombres, incluso si éstos no duran más que su materia en fusión y dejar rápidamente lugar a la división, a la traición", Deleuze y Guattari, 1991, p. 167.

${ }^{18}$ Sobre la duración como rasgo del Estado, cfr. Abad y Amador, 2018, p. 41.
} 


\section{Referencias}

ABAD, S.; CANTARELLI, M. Habitar el Estado. Buenos Aires: Hydra, 2012.

ABAD, S.; AMADOR, E. (comps.). El fantasma en la máquina. Sobre la formación de los agentes estatales. Buenos Aires: Hydra, 2018.

ALLIEZ, E.; LAZZARATO, M. Guerres et capital Paris. Amsterdam, 2016.

BADIOU, A. Deleure: El clamor del ser. Trad. Dardo Scavino. Manantial: Buenos Aires, 1997.

BADIOU, A. Le fascisme de la pomme de terre (bajo el pseudónimo G. Peyrol). In: La situation actuelle sur le front de la philosophie. Paris: Maspero, 1977. p. 42-52.

BELL, J. Deleuze and Guattari 's What is Philosophy? Edinburgh: Edinburgh University Press, 2016.

BELL, J. Whistle While You Work: Deleuze and the Spirit of Capitalism. In: JUN, N.; SMITH, D. W. Deleuze and Ethics. Edinburgh: Edinburgh University Press, 2011. p. 5-20.

BOLTANSKI, L.; CHIAPPELLO, E. Le nouvel esprit de capitalisme. Paris: Gallimard, 1999.

BUTLER, J. Cuerpos aliados y lucha política. Barcelona: Paidós, 2017.

CLISBY, D. ¿El dualismo secreto de Deleuze? Versiones en disputa de la relación entre lo virtual y lo actual. Trad. Pablo Pachilla. Ideas, revista de filosofía moderna y contemporánea, n. 4, p. $120-147,2016$.

CLISBY, D.; BOWDEN, S. Introduction: The Virtual, the Actual and the Intensive: Contentions, Reflections and Interpretations. Deleure Studies, n. 11.2, p. 153-155, 2017.

COLSON, D. A Little Philosophical Lexicon of Anarchism from Proudhon to Deleuze. Trad. Jesse Cohn. Colchester / New York / Port Watson: Minor Compositions, 2019.

CUNINGHAME, P. Resistiendo al imperio. Autonomía, autonomismo y movimientos sociales latinoamericanos. Veredas, n. 21, p. 149-166, 2010.

DELANDA, M. History and Science. New York: Antropos, 2010.

DELANDA, M. "Space: Extensive and Intensive, Actual and Virtual". In: BUCHANAN, I.; LAMBERT, G. (eds.). Deleuze and Space. Edinburgh University Press: Edimburgo, 2005.

DELEUZE, G. Pintura, el concepto de diagrama. Trad. Equipo Editorial Cactus. Buenos Aires: Cactus, 2007.

DELEUZE, G. "L'immanence: une vie...". In: Deux régimes de fous. Paris: Minuit, 2003. p. 359-363.

DELEUZE, G. Francis Bacon, logique de la sensation. Paris: Seuil, 2002. 
DELEUZE, G. L'actuel et le virtuel. In: DELEUZE, G. Y PARNET, C. Dialogues. Paris: Flammarion, 1996. p. 177-185.

DELEUZE, G. Logique du sens. Paris: Minuit, 1969.

DELEUZE, G. Différence et répétition. Paris: PUF, 1968.

DELEUZE, G.; GUATTARI, F. Qu'est-ce que la philosophie? Paris: Minuit, 1991.

DELEUZE, G.; GUATTARI, F. Mille Plateaux. Paris: Minuit, 1980.

DELEUZE, G.; GUATTARI, F. L'anti-Oedipe. Paris: Minuit,1972.

DOTTI, J. Filoloque. In: SCHMITT, C. La tiranía de los valores. Buenos Aires: Hydra, 2009.

DOTTI, J. Notas complementarias. Deus Mortalis, n. 10, p. 309-524, 2011-2012.

FERREYRA, J. Deleuze y el Estado. Deus Mortalis, n. 10, p. 265-286, 2011-2012.

FERREYRA, J. Una apología del Estado como aparato de captura en Deleuze y Guattari. Nombres, n. 30, p. 239-262, 2016.

GRAY AN HEERDEN, C.; ELOFF, A. Deleuze and Anarchism. Edinburgh: Edinburgh University Press, 2018.

HALLWARD, P. Out of This World: Deleuze and the Philosophy of Creation. Londres / Nueva York: Verso, 2006.

HUGHES, J. Deleuze's Difference and Repetition. Londres/Nueva York: Continuum, 2009.

JOUER, M. El "progresismo fascista", Marx, Deleuze \& Guattari. Esclavitud libidinal y sujeción social en el patriarcado estatal y capitalista. Buenos Aires: Colectiva Moi Non Plus, 2018.

KARSANTI, B. Le capitalisme au présent. Multitudes, n. 3, p. 143-160, 2000.

KCENIG, G. Leçons sur la Philosophie de Gilles Deleuze. Un Système kantien. Une Politique anarcho-capitaliste. París: Ellipses, 2013.

KUSCH, R. América Produnda. In: Obras Completa, tomo II. Rosario: Ross, 2000.

MARX, K. Elementos fundamentales para la crítica de la economía política (Grundrisse). Trad. Pedro Scarón. Buenos Aires: Siglo XXI, 1971.

MASSUMI, B. A User's Guide to Capitalism and Schizophrenia: Deviations from Deleuze and Guattari. Cambridge: MIT Press, 1993.

MC NAMARA, R. Deleure y la ontología del espacio. Tesis doctoral. Buenos Aires: FFyLUBA, 2019.

MENGUE, Ph. Deleure et la question de la démocratie. Paris: L'Harmattan, 2003.

MICHÉA, J.-C. Les mystères de la Gauche, de l'idéal des lumières au triomphe du capitalisme absolu. Paris: Flammarion, 2013. 
NEGRI, A. La Forma Stato. Giangiacomo Feltrinelli Editore: Milan, 1977.

PÁL PELBART, P. Capitalismo rizomático. In: Vida capital, Ensaios de biopolítica. Iluminuras: San Pablo, 2016.

RAMPAZZO BAZZAN, M. "Machine de guerre" ou "machine a guérilla", la machine de guerre comme analyseur des théorisations de la guérilla urbaine en R.F.A. depuis le 2 juin 1967. In: . MISAVLJEVIC, V.; SIBERTIN-BLANC, G. (éd.). Deleuze et la violence. Toulouse: EuroPhilosophie, 2017.

ROFFE, J. Deleuze's Concept of Quasi-cause. Deleuze Studies, n. 11.2, p. 278-294, 2017.

ROFFE, J. Badiou's Deleure. Montreal / Kingston: McGill-Queen's University Press, 2012.

SANTAYA, G. Interferencias matemáticas en la filosofía de Gilles Deleure: ontología desarrollada more topológico. Tesis (Doctorado) — Universidad de Buenos Aires, 2019, inédita.

SMITH, D. W. Essays on Deleure. Edinburgh: Edinburgh University Press, 2012.

SOMERS-HALL, H. Hegel, Deleuze, and the Critique of Representation: Dialectics of Negation and Difference. New York: New York Press, 2012.

SZTULWARK, D. Notas para la investigación politica en el seno de las paradojas del post-neoliberalismo. Lobo suelto, 2013. Disponible en: http:/ /anarquiacoronada.blogspot.com/2013/04/cartografias-politicas-notas-para-la.html. Accesso em: 5 abr. 2019.

THUBORN, N. Deleure, Marx and Politics. New York/London: Routdlege, 2003.

WILLIAMS, J. Gilles Deleuze's Difference and Repetition: A Critical Introduction and Guide, Edinburgh: Edinburgh University Press, 2003.

WILLIAMS, J. The Transversal Thought of Gilles Deleuze: Encounters and influences. Manchester: Clinamen Press, 2005.

RECIBIDO: $10 / 04 / 2019$

APROBADO: $14 / 06 / 2020$

RECEIVED: 04/10/2019

APPROVED: 06/14/2020 